\title{
Monthly Crustal Loading Corrections for Satellite Altimetry
}

\author{
R. D. RAY AND S. B. LUTHCKE \\ NASA Goddard Space Flight Center, Greenbelt, Maryland \\ T. VAN DAM \\ University of Luxembourg, Walferdange, Luxembourg
}

(Manuscript received 27 July 2012, in final form 27 November 2012)

\begin{abstract}
Satellite altimeter measurements of sea surface height include a small contribution from vertical motion of the seafloor caused by crustal loading. Loading by ocean tides is routinely allowed for in altimeter data processing. Here, loading by nontidal fluids of the atmosphere, ocean, and terrestrial hydrosphere is examined. The crustal deformation can be computed from either geophysical models or from Gravity Recovery and Climate Experiment (GRACE) gravity inversions of mass variability. The loading corrections are found to be very small, rarely exceeding a few millimeters. Nonetheless, they form a significant correction to altimetric determinations of global mean sea level. The correction is most important at the annual cycle and should be accounted for when attempting to balance the global sea level budget.
\end{abstract}

\section{Introduction}

Correcting satellite altimeter measurements for ocean tidal loading - that is, for the elastic deformation of the solid earth induced by the weight of the overlying ocean tide-is a standard part of altimetry data processing (Francis and Mazzega 1990). Correcting altimetry for loading by other geophysical fluids has rarely been considered, a notable exception being a study by Kuo et al. (2008). In part this neglect has persisted because other fluids were so poorly known, at least on global scales. Yet over the past few years global fluid models have been improving and their loading predictions are now being tested against direct deformation measurements obtained with global geodetic networks (e.g., Schuh et al. 2004; Gegout et al. 2010; van Dam et al. 2012). Moreover, since 2003 the varying movement of fluid masses across the globe has been monitored directly by the Gravity Recovery and Climate Experiment (GRACE) gravity satellites, and these data can also be used to compute and test loading deformation (e.g., Davis et al. 2004; van Dam et al. 2007; Tregoning et al.

Corresponding author address: R. D. Ray, NASA GSFC, Code 698, Greenbelt, MD 20771.

E-mail: richard.ray@nasa.gov
2009; Horwath et al. 2010; Tesmer et al. 2011)(see the appendix).

This paper examines the utility of nontidal loading corrections for satellite altimetry. Several considerations lead us to conclude that, with an important exception, such corrections are not merited on a routine basis. The corrections are still imperfectly known, although it is clear they are very small, rarely exceeding a few millimeters over the ocean. More importantly, in some situations no correction is desirable because it may be more straightforward and useful to analyze absolute (geocentric) sea surface heights rather than heights relative to the seafloor. Dynamical equations of motion can presumably be formulated for either case, as they are for tides (Hendershott 1981). Tamisiea et al. (2010) have recently explored how fluid loading and self-attraction modify the observed seasonal signal of the ocean (e.g., in tide gauge data), but this is a quite separate issue from correcting altimetry for the geometrical effect of crustal motion from loading.

The one exception for which nontidal fluid loading correction for altimetry appears especially important concerns the altimetric global mean sea level time series. We examine this effect in some detail below. At the annual cycle, the correction exceeds $10 \%$ of the primary signal. This is significant for any study attempting to balance the mass and steric components of global sea 
level (e.g., Lombard et al. 2007; Leuliette and Willis 2011).

\section{Monthly loading estimates}

Loading deformation is computed here from two starkly different mass load sources: GRACE monthly gravity solutions (with solid earth effects removed) and a set of global geophysical fluid models. The latter comprise three distinct and not necessarily consistent models of the atmosphere, the ocean, and the terrestrial water storage. The time-varying atmospheric mass is modeled from the 3-hourly operational products of the European Centre for Medium-Range Weather Forecasts (ECMWF), supplied to us in the form of spherical harmonic series by our colleague J.-P. Boy (University of Strasbourg). Time-varying ocean mass is modeled with the Ocean Model for Circulation and Tides (OMCT) product (Dobslaw and Thomas 2007), which is supplied by the GRACE project team at GeoForschungsZentrum, Potsdam, Germany. OMCT is a 3D primitive equation ocean model forced by wind stress, atmospheric surface pressure, temperature, and freshwater fluxes from 6-h ECMWF operational analyses. Terrestrial water storage is modeled with the Global Land Data Assimilation System (GLDAS)/Noah system at Goddard Space Flight Center (GSFC) (Rodell et al. 2004). By definition these mass changes occur only on land, but their crustal deformation extends into ocean regions, so it is important to include them. Note that the GLDAS data are invalid over mountain glaciers and the major polar ice sheets owing to the lack of a dynamic ice model, so we have forced GLDAS mass variability to zero in those regions. To facilitate comparison with our GRACE results, all the above-mentioned geophysical fluid models have been computed as a monthly average time series, although there is clearly no impediment to using finer resolution in time.

The primary GRACE solutions used here correspond to GSFC version 9, an update to those described by Luthcke et al. (2006); see also Luthcke et al. (2013). The GRACE data allow us to deduce mass fluxes in the whole earth system; to obtain the surface-fluid masses of interest here, we must remove any solid earth effects. The largest of these is from postglacial rebound. We employ a model of global isostatic adjustment from Pleistocene ice unloading roughly equivalent to that described by Paulson et al. (2007). A second model for the response from the Little Ice Age in and around Alaska is adopted from Larsen et al. (2004).

The GSFC GRACE data processing employed the same time-varying forward models for the atmosphere, ocean, and terrestrial water storage as described above for necessary antialiasing prior to estimation of monthly time-variable gravity. Subsequently, these forward models were all restored as monthly averages [the glacial isostatic adjustment (GIA) models were obviously not restored]. The gravity solutions were smoothed by a $600-\mathrm{km}$ Gaussian smoother.

Given geopotential Stokes coefficients $C_{n m}, S_{n m}$ derived either from GRACE or models, the elastic vertical deformation of the earth's surface can be computed in the usual way (e.g., Kusche and Schrama 2005; van Dam et al. 2007):

$$
\begin{aligned}
s_{h}(\theta, \phi, t)= & R \sum_{n=1}^{N} \sum_{m=0}^{n} \tilde{P}_{n}^{m}(\cos \theta)\left[C_{n m}(t) \cos m \phi\right. \\
& \left.+S_{n m}(t) \sin m \phi\right] \frac{h_{n}^{\prime}}{1+k_{n}^{\prime}}
\end{aligned}
$$

where $R$ is the earth's radius, $\tilde{P}_{n}^{m}$ are associated Legendre functions, and $h_{n}^{\prime}$ and $k_{n}^{\prime}$ are displacement and potential loading numbers. We set $N=60$.

The degree $n=1$ terms in (1) merit special attention since they depend on the adopted geodetic reference frame. The realized frame for satellite altimetry is somewhat controversial and depends on details of the orbit determination. Normally, it is most useful to have sea surface heights in a center-of-figure (CF) frame, which corresponds to the system in which in situ ocean measurements are made. A satellite altimeter orbits the center of mass $(\mathrm{CM})$ of the whole earth system, but with the present orbit determination techniques used for the Ocean Topography Experiment (TOPEX)/Poseidon (T/P) and Jason satellites (Cerri et al. 2010), the primary tracking data tend to force the computed ephemerides (at least in the $z$ direction) toward the $\mathrm{CF}$ frame, or more accurately toward the center-of-network $(\mathrm{CN})$ frame of the satellite laser ranging network (this is probably not the case for GPS-based orbits, which appear to be more closely tied to a CM frame, but such orbits do not form the primary solution for the whole T/P-Jason time series); see, in particular, the discussion by Melachroinos et al. (2013). Below, we therefore assume the altimetric heights are in an approximate $\mathrm{CF}$ frame and we adopt loading Love numbers appropriate for that frame (Blewitt 2003), specifically $h_{1}^{\prime}=-0.268$ and $k_{1}^{\prime}=0.021$. In the future as orbit determination methods evolve, Love numbers consistent with some other frame may be more appropriate.

An additional point concerning the reference frame is that satellite-to-satellite ranging is essentially insensitive to degree 1 terms, so all purely GRACE gravity solutions yield Stokes coefficients only for degrees 2 and higher. We therefore supplement our GRACE solutions 

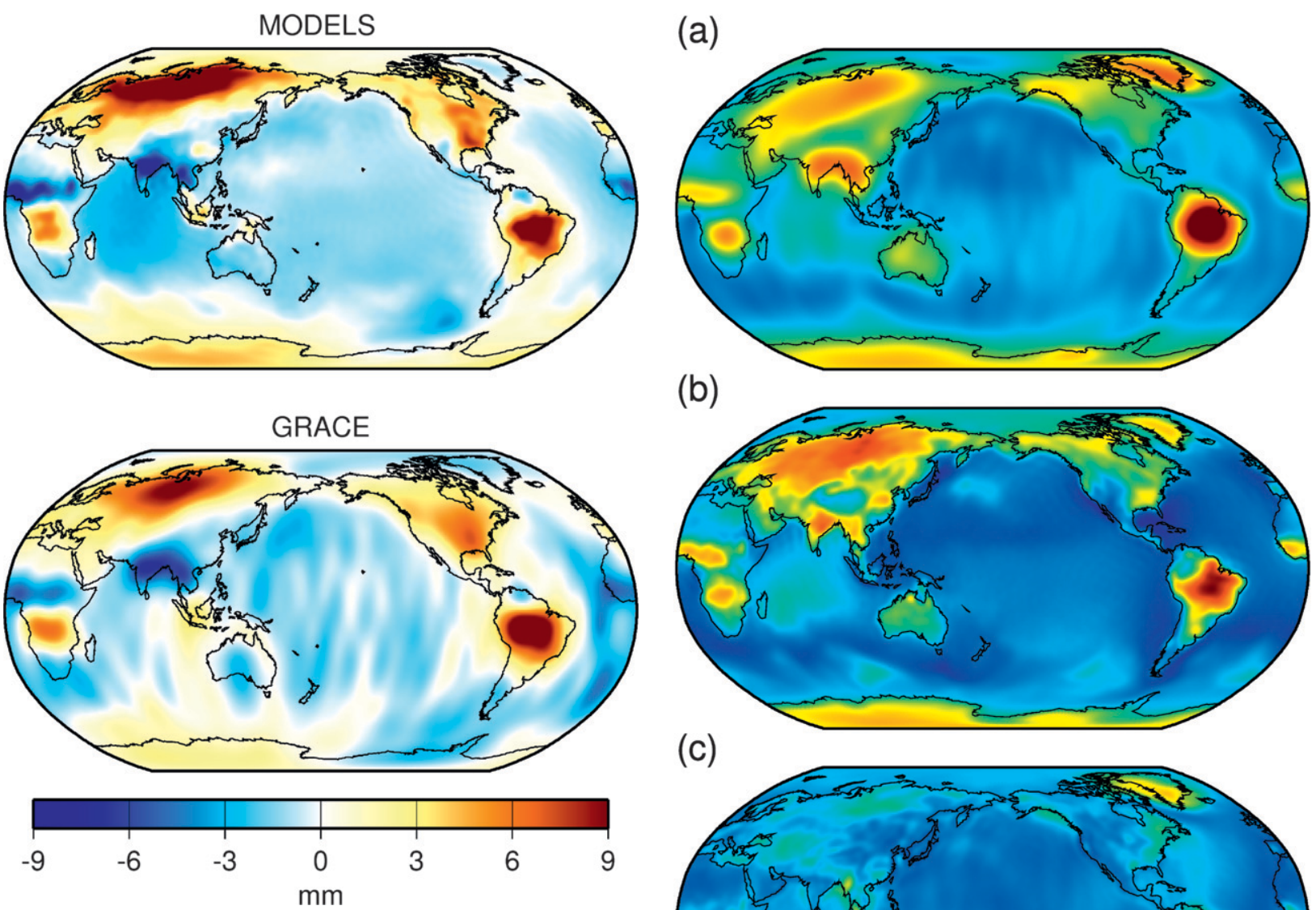

FIG. 1. Mean vertical deformation (mm) for September 2006 from oceanic, atmospheric, and hydrological loading. (top) From models of the three geophysical fluids. (bottom) From analysis of GRACE satellite gravity data. Color scale saturates in some regions, e.g., high over Brazil exceeds $13 \mathrm{~mm}$.

with the geocenter model of Swenson et al. (2008), which is based on inferring degree 1 terms from a combined analysis of the OMCT ocean model and monthly GRACE solutions. Our adopted geophysical fluid models have no such lacunas at degree 1.

An example of mean monthly vertical deformation is shown in Fig. 1 for September 2006. The two charts shown, from geophysical models and from GRACE data, agree fairly well qualitatively for the largest-scale basin signals, although details clearly differ. The charts are dominated by large signals over continental regions, of the type now familiar from GRACE analyses (e.g., Tapley et al. 2004). The largest signals, reflecting hydrological loading (or unloading), occur over the Amazon basin of South America. In that region hydrological loading is generally low in September, following the July-August seasonal low in the annual precipitation cycle (Betts et al. 2005), so the vertical deformation is correspondingly high, reaching nearly $+14 \mathrm{~mm}$. The

(b)

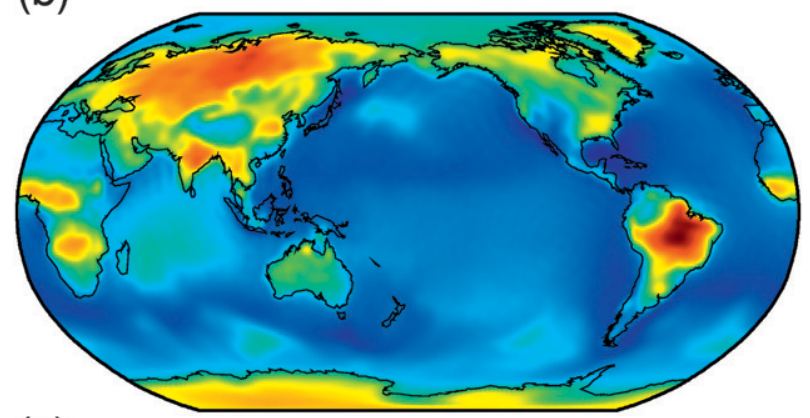

(c)

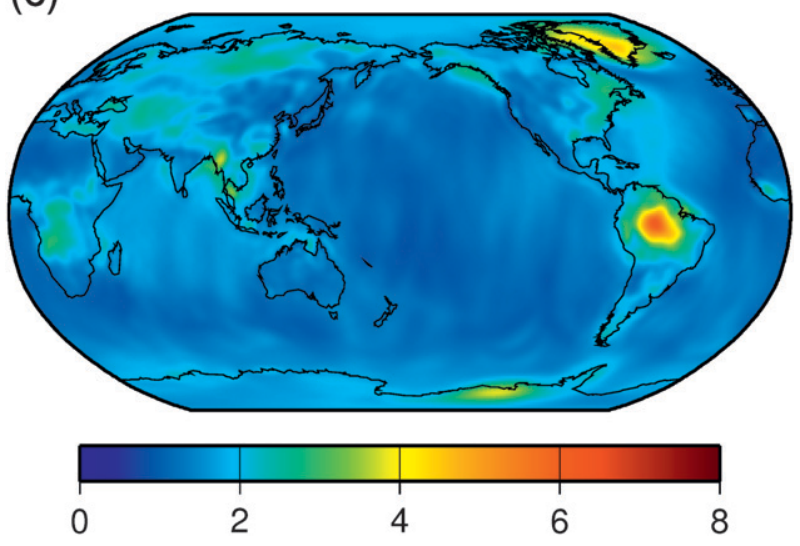

FIG. 2. Standard deviation $(\mathrm{mm})$ of monthly vertical loading signals over $5 \mathrm{yr}$ from (a) GRACE solutions and (b) geophysical fluid models. (c) Standard deviation of the differences between GRACE and the models.

signals over the oceans, which are more relevant to our purposes, are much smaller and do not exceed $3 \mathrm{~mm}$.

A more quantitative comparison of the model and GRACE deformation results is shown in Fig. 2, which shows standard deviations over 6 years for the GRACE and model-based signals and for model-GRACE differences. Horwath et al. (2010) showed data similar to Fig. 2a and compared them with vertical motion estimates from GPS stations; they found reasonably good agreement over most continental sites, including the relatively large deformation signals we observe over Antarctica, presumably mostly from atmospheric loading. Note that 


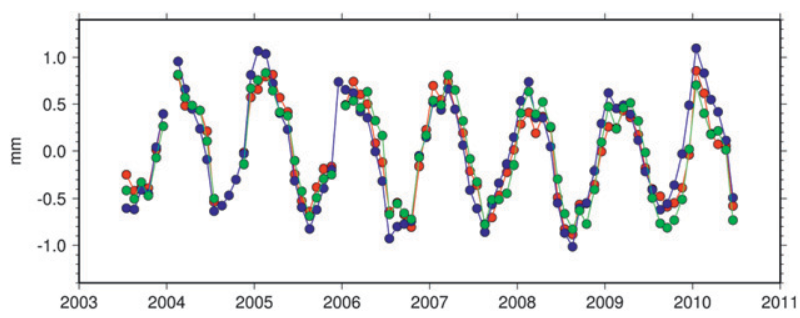

FIG. 3. Mean vertical crustal deformation over the global ocean, based on (blue) models of the ocean, atmosphere, and terrestrial hydrology; (red) GRACE gravity solutions at GSFC; and (green) GRACE gravity solutions at the University of Texas (release 4). We propose using one of these time series to correct altimetric estimates of global mean sea level for effects of crustal deformation.

the fluid models show much reduced deformation over Greenland and southern Alaska, a result of our having to mask GLDAS errors in those regions.

The largest ocean signals appear to arise over the Indian Ocean, where the standard deviation is about $3 \mathrm{~mm}$, and in a few well-known hot spots for barotropic variability in the Southern Ocean (Fu 2003). In general the GRACE ocean signals tend to be somewhat larger than the model-based signals, probably owing to background noise levels in the gravity inversions. The standard deviation of the differences over oceans is small and never exceeds $2 \mathrm{~mm}$. However, these differences are comparable to, and sometimes slightly higher than, the model-based signals, most notably in the Atlantic Ocean. This does emphasize the difficulty of reliably extracting or estimating such small deformation signals over oceanic regions (cf. Quinn and Ponte 2012).

Because they are so small, and potentially somewhat unreliable, it is doubtful that such computed vertical deformations will form a correction in any application of satellite altimetry in the near future. There is, however, one important exception, which is the topic of the remainder of this paper.

\section{Corrections for global mean sea level}

The current rate of global mean sea level rise, as determined by satellite altimetry, is approximately $3.0 \pm$ $0.4 \mathrm{~mm} \mathrm{yr}^{-1}$, sometimes quoted slightly higher or slightly lower depending on the exact time period under analysis (Cazenave and Llovel 2010; Beckley et al. 2010). Atop this long-term trend is a strong annual cycle, reaching amplitudes of almost $5 \mathrm{~mm}$ in sea level and roughly twice that in ocean mass (Chen et al. 2005; Leuliette and Willis 2011). Attempts to balance the observed sea level time series from altimetry against mass flux estimates from GRACE and steric estimates from
TABLE 1. Mean annual crustal deformation over the global ocean.

\begin{tabular}{lcc}
\hline \hline \multicolumn{1}{c}{ Source } & Amplitude $(\mathrm{mm})$ & Phase lag $\left(^{\circ}\right)^{*}$ \\
\hline Geophysical fluid models & $0.75 \pm 0.04$ & $327 \pm 3$ \\
GRACE: GSFC version 9 & $0.64 \pm 0.03$ & $338 \pm 3$ \\
GRACE: University of Texas & $0.68 \pm 0.03$ & $343 \pm 3$ \\
Center for Space Research & & \\
(CSR) version 4 & & \\
\hline
\end{tabular}

* Relative to the time of the spring equinox.

Argo and other hydrographic measurements have been reported by Lombard et al. (2007), Willis et al. (2008), Leuliette and Miller (2009), and others.

If vertical crustal loading causes the mean ocean basin to move toward or away from the altimeter, then adjustment of the altimetric global mean sea level time series is clearly warranted. The question is whether the adjustment is significant or not. We find that it is, at least for the annual cycle.

The time series shown in Fig. 3 were formed by averaging over the global ocean each of our monthly estimates of vertical deformation. Each series is dominated by an annual cycle, of amplitude about $0.7 \mathrm{~mm}$, with models and GRACE in reasonably close agreement. Because GRACE analyses sometimes differ according to the adopted methodology for processing satellitesatellite range rate data, we have added to this diagram a time series based on the gravity solutions from the University of Texas (updated from Tapley et al. 2004).

The strong annual cycle in Fig. 3 peaks roughly in February of each calendar year. Estimated amplitudes and phases of each of the three time series are summarized in Table 1, where quoted uncertainties correspond to one standard error. Within those uncertainties the two GRACE solutions are very consistent, but the geophysical models give an annual amplitude slightly larger and phase slightly earlier. The degree 1 terms contribute an important part to this annual signal; for the GSFC GRACE solution we find the degree 1 terms alone have an amplitude of $0.12 \mathrm{~mm}$ and phase lag of $326^{\circ}$. Estimated amplitudes for the semiannual cycle are all very small, less than $0.04 \mathrm{~mm}$, and can be safely ignored at this stage.

Note that all annual phases in this paper are lags relative to the mean longitude of the sun-that is, relative (to acceptable precision) to the passage of the sun past the vernal equinox-which is the fundamental cyclic variable for seasonal phenomena. One full cycle of the sun's mean longitude in fact defines one tropical year (Green 1985). To convert to phases relative to the beginning of a calendar year, which corresponds to nothing physical, add approximately $80^{\circ}$. 
TABLE 2. Altimetric global mean sea level, annual cycle.

\begin{tabular}{llll}
\hline \multicolumn{1}{c}{ Authors } & \multicolumn{1}{c}{ Period } & \multicolumn{1}{c}{$\begin{array}{c}\text { Amplitude } \\
(\mathrm{mm})\end{array}$} & $\begin{array}{c}\text { Phase lag } \\
\left({ }^{\circ}\right)^{*}\end{array}$ \\
\hline Beckley et al. (2010) & $1993-2010$ & $4.3 \pm 0.5$ & $208 \pm 7$ \\
Chen et al. (2005) & $2002-04$ & 4.2 & 216 \\
Leuliette and Miller (2009) & $2004-07$ & $4.0 \pm 1.6$ & $162 \pm 16$ \\
Vinogradov et al. (2008) & $1992-2004$ & $5.1 \pm 1.5$ & $232 \pm 17$ \\
Willis et al. (2008) & 2003-07 & $3.2 \pm 1.3$ & $170 \pm 23$ \\
\hline
\end{tabular}

* Relative to the spring equinox.

The data in Table 1 correspond to loading over the whole global ocean. The values change if only part of the ocean is considered. Often the polar oceans are ignored, since the T/P and Jason satellites' turning latitudes are $\pm 66^{\circ}$. If we employ, for example, the ocean altimeter mask used by Willis et al. (2008), then the GSFC GRACE values of Table 1 become somewhat larger and slightly shifted in phase: amplitude of $0.85 \mathrm{~mm}$ and phase lag of $333^{\circ}$.

To understand the significance of the annual load signals as a potential correction to satellite altimetry, Table 2 tabulates a selection of published altimeter-based estimates of the annual cycle in global mean sea level [the line for Beckley et al. (2010) is not in their original paper but has been computed by us from their time series]. There is some understandable scatter in the estimates, in part owing to different time periods analyzed and also in part because some authors used very short periods. We can expect sharper definition as all time series lengthen. Nonetheless, with listed amplitudes falling between 3.2 and $5.1 \mathrm{~mm}$, it is clear that a $0.7-\mathrm{mm}$ correction for vertical loading of the crust, as we propose here, is a significant fraction of the whole and should not be neglected.

Close examination of Fig. 3 shows a slight negative trend in all time series, except for the final year or two, which turns upward. Estimated linear fits to the time series are $-0.022 \pm 0.014$ and $-0.056 \pm 0.012 \mathrm{~mm} \mathrm{yr}^{-1}$ for models and GRACE, respectively, the former being insignificant at the $95 \%$ level. For several reasons we are not inclined at this stage to give much credence to these trends. The jump at the end suggests possible interannual variability, rather than secular trend, so any trend observed over a few years may be short lived. More importantly, our quoted standard errors do not adequately account for the myriad systematic errors in play. For example, while estimates of the seasonal geocenter motion nowadays appear fairly robust, determination of any secular trend is far more problematic (Wu et al. 2012). Errors in GIA modeling would also affect the GRACE-derived trend. The GIA correction to GRACE accounts for a trend of roughly $-0.06 \mathrm{~mm} \mathrm{yr}^{-1}$ in Fig. 3; the error in the GIA correction is unknown but could be substantial (Guo et al. 2012). Similarly, secular trends in geophysical models are generally uncertain, especially (as here) when the models are developed as independent and potentially inconsistent fluid systems. Efforts are being made to overcome some of these difficulties (e.g., Dobslaw et al. 2010), and further improvements can be expected as modeling, measurement systems, and geodetic reference frames improve. Fortunately, a secular trend of even $-0.056 \mathrm{~mm} \mathrm{yr}^{-1}$ is insignificant relative to our current uncertainty in altimetric sea level rise, which is generally considered about $\pm 0.4 \mathrm{~mm} \mathrm{yr}^{-1}$. Hence, the deformation correction proposed here will be most useful for studies of the earth's annual water cycle.

Acknowledgments. This work was supported by NASA IDS Sea Level and GRACE investigations. JeanPaul Boy provided essential help in obtaining the geophysical fluid models. We thank Frank Lemoine, David Rowlands, and John Ries for the useful discussions.

\section{APPENDIX}

\section{Recipe for Computing Deformation from GRACE Data}

This appendix lays out a recipe for computing crustal deformation from the GRACE gravity solutions as released by the GRACE project centers. The discussion is meant for experts in these datasets and will be mostly unintelligible unless the reader is familiar with relevant project documentation, primarily the project report by Flechtner (2007).

Beginning with the monthly Stokes coefficients, the steps are as follows:

(i) If desired, replace the gravitational $J_{2}$ coefficients with those produced by analysis of satellite laser ranging.

(ii) Augment the nominal GRACE coefficients with the degree 1 terms from Swenson et al. (2008) or another relevant model.

(iii) Add back coefficients for the monthly GAC product, including the degree 1 terms.

(iv) Remove glacial isostatic adjustment via a relevant model.

(v) Remove a mean of all spherical harmonic coefficients over the given time period.

(vi) Perform Gaussian smoothing (in space or spherical harmonic domain).

(vii) Use Eq. (1) to compute deformation. 


\section{REFERENCES}

Beckley, B. D., N. P. Zelensky, S. A. Holmes, F. G. Lemoine, R. D. Ray, G. T. Mitchum, S. D. Desai, and S. T. Brown, 2010: Assessment of the Jason-2 extension to the TOPEX/Poseidon, Jason-1 sea-surface height time series for global mean sea level monitoring. Mar. Geod., 33, 447-471.

Betts, A. K., J. H. Hall, P. Viterbo, A. Dai, and J. Marengo, 2005: Hydrometeorology of the Amazon in ERA-40. J. Hydrometeor., 6, 764-774.

Blewitt, G., 2003: Self-consistency in reference frames, geocenter definition, and surface loading of the solid earth. J. Geophys. Res., 108, 2103, doi:10.1029/2002JB002082.

Cazenave, A., and W. Llovel, 2010: Contemporary sea level rise. Annu. Rev. Mar. Sci., 2, 145-173.

Cerri, L., and Coauthors, 2010: Precision orbit determination standards for the Jason series of altimeter missions. Mar. Geod., 33, 379-418.

Chen, J. L., C. R. Wilson, B. D. Tapley, J. S. Famiglietti, and M. Rodell, 2005: Seasonal global mean sea level change from satellite altimetry, GRACE, and geophysical models. J. Geod., 79, 532-539.

Davis, J. L., P. Elósegui, J. X. Mitrovica, and M. E. Tamisiea, 2004: Climate-driven deformation of the solid Earth from GRACE and GPS. Geophys. Res. Lett., 31, L24605, doi:10.1029/ 2004GL021435.

Dobslaw, H., and M. Thomas, 2007: Simulation and observation of global ocean mass anomalies. J. Geophys. Res., 112, C05040, doi:10.1029/2006JC004035.

_, R. Dill, A. Grötzsch, A. Brzeziński, and M. Thomas, 2010: Seasonal polar motion excitation from numerical models of atmosphere, ocean, and continental hydrosphere. J. Geophys. Res., 115, B10406, doi:10.1029/2009JB007127.

Flechtner, F., 2007: AOD1B product description document for product releases 01 to 04 . Gravity Recovery and Climate Experiment Tech. Rep. GRACE 327-750, GR-GFZ-AOD-0001, GeoForschungsZentrum, 43 pp.

Francis, O., and P. Mazzega, 1990: Global charts of ocean tide loading effects. J. Geophys. Res., 95 (C7), 11 411-11 424.

Fu, L.-L., 2003: Wind-forced intraseasonal sea level variability of the extratropical oceans. J. Phys. Oceanogr., 33, 436449

Gegout, P., J.-P. Boy, J. Hinderer, and G. Ferhat, 2010: Modeling and observation of loading contribution to time-variable GPS sites positions. Gravity, Geoid and Earth Observation, S. P. Mertikas, Ed., International Association of Geodesy Symposia, Vol. 135, Springer-Verlag, 651-659.

Green, R. M., 1985: Spherical Astronomy. Cambridge University Press, $536 \mathrm{pp}$

Guo, J. Y., Z. W. Huang, C. K. Shum, and W. van der Wal, 2012: Comparisons among contemporary glacial isostatic adjustment models. J. Geodyn., 61, 129-137.

Hendershott, M. C., 1981: Long waves and ocean tides. Evolution of Physical Oceanography, B. A. Warren and C. Wunsch, Eds., MIT Press, 292-341.

Horwath, M., A. Rülke, M. Fritsche, and R. Dietrich, 2010: Mass variation signals in GRACE products and in crustal deformation from GPS: A comparison. System Earth via GeodeticGeophysical Space Techniques, F. Flechtner et al., Eds., Springer-Verlag, 399-406.

Kuo, C.-Y., and Coauthors, 2008: Southern Ocean mass variation studies using GRACE and satellite altimetry. Earth Planets Space, 60, 477-485.
Kusche, J., and E. J. O. Schrama, 2005: Surface mass redistribution inversion from global GPS and Gravity Recovery and Climate Experiment (GRACE) gravity data. J. Geophys. Res., 110, B09409, doi:10.1029/2004JB003556.

Larsen, C. F., R. J. Motyka, J. T. Freymueller, K. A. Echelmeyer, and E. R. Ivins, 2004: Rapid viscoelastic uplift in southeast Alaska caused by post-Little Ice Age glacial retreats. Earth Planet. Sci. Lett., 237, 548-560.

Leuliette, E. W., and L. Miller, 2009: Closing the sea level rise budget with altimetry, Argo, and GRACE. Geophys. Res. Lett., 36, L04608, doi:10.1029/2008GL036010.

, and J. K. Willis, 2011: Balancing the sea level budget. Oceanography, 24, 122-130.

Lombard, A., and Coauthors, 2007: Estimation of steric sea level variations from combined GRACE and Jason-1 data. Earth Planet. Sci. Lett., 254, 194-202.

Luthcke, S. B., D. D. Rowlands, F. G. Lemoine, S. M. Klosko, D. S Chinn, and J. J. McCarthy, 2006: Monthly spherical harmonic gravity field solutions determined from GRACE inter-satellite range-rate data alone. Geophys. Res. Lett., 33, L02402, doi:10.1029/2005GL024846.

_ T. J. Sabaka, B. D. Loomis, A. A. Arendt, J. J. McCarthy, and J. Camp, 2013: Antarctica, Greenland, and Gulf of Alaska land ice evolution from an iterated GRACE mascon solution. J. Glaciol., in press.

Melachroinos, S. A., F. G. Lemoine, N. P. Zelensky, D. D. Rowlands, S. B. Luthcke, and O. Bordyugov, 2013: The effect of geocenter motion on Jason-2 orbits and the mean sea level Adv. Space Res., 51, 1323-1334, doi:10.1016/j.asr.2012.06.004.

Paulson, A., S. Zhong, and J. Wahr, 2007: Inference of mantle viscosity from GRACE and relative sea level data. Geophys. J. Int., 171, 497-508.

Quinn, K. J., and R. M. Ponte, 2012: High frequency barotropic ocean variability observed by GRACE and satellite altimetry. Geophys. Res. Lett., 39, L07603, doi:10.1029/ 2012GL051301.

Rodell, M., and Coauthors, 2004: The Global Land Data Assimilation System. Bull. Amer. Meteor. Soc., 85, 381-394.

Schuh, H., G. Estermann, J.-F. Crétaux, M. Bergé-Nguyen, and T. van Dam, 2004: Investigation of hydrological and atmospheric loading by space geodetic techniques. Satellite Altimetry for Geodesy, Geophysics and Oceanography, C. Hwang C. K. Shum, and J. Li, Eds., International Association of Geodesy Symposia, Vol. 126, Springer-Verlag, 123-132.

Swenson, S., D. P. Chambers, and J. M. Wahr, 2008: Estimating geocenter variations from a combination of GRACE and ocean model output. J. Geophys. Res., 113, B08410, doi:10.1029/ 2007JB005338.

Tamisiea, M. E., E. M. Hill, R. M. Ponte, J. L. Davis, I. Velicogna, and N. T. Vinogradova, 2010: Impact of self-attraction and loading on the annual cycle in sea level. J. Geophys. Res., 115, C07004, doi:10.1029/2009JC005687.

Tapley, B. D., S. Bettadpur, J. C. Ries, P. F. Thompson, and M. M. Watkins, 2004: GRACE measurements of mass variability in the Earth system. Science, 305, 503-505.

Tesmer, V., P. Steigenberger, T. van Dam, and T. Mayer-Gürr, 2011: Vertical deformations from homogeneously processed GRACE and global GPS long-term series. J. Geod., 85, 291310.

Tregoning, P., C. Watson, R. Ramillien, H. McQueen, and J. Zhang, 2009: Detecting hydrologic deformation using GRACE and GPS. Geophys. Res. Lett., 36, L15401, doi:10.1029/ 2009GL038718. 
van Dam, T., J. Wahr, and D. Lavallée, 2007: A comparison of annual vertical crustal displacements from GPS and Gravity Recovery and Climate Experiment (GRACE) over Europe. J. Geophys. Res., 112, B03404, doi:10.1029/2006JB004335.

X. Collilieux, J. Wuite, Z. Altamimi, and J. Ray, 2012: Nontidal ocean loading: Amplitudes and potential effects in GPS height time series. J. Geod., 86, 1043-1057.

Vinogradov, S. V., R. M. Ponte, P. Heimbach, and C. Wunsch, 2008: The mean seasonal cycle in sea level estimated from a data-constrained general circulation model. J. Geophys. Res., 113, C03032, doi:10.1029/2007JC004496.

Willis, J. K., D. P. Chambers, and R. S. Nerem, 2008: Assessing the globally averaged sea level budget on seasonal to interannual timescales. J. Geophys. Res., 113, C06015, doi:10.1029/ 2007JC004517.

Wu, X., J. Ray, and T. van Dam, 2012: Geocenter motion and its geodetic and geophysical implications. J. Geodyn., 58, $44-61$. 